\title{
Life cycle design of building elements: selection criteria and case study application
}

\author{
A. Basti \\ Department of Technologies for Built Environment, \\ University "G. d'Annunzio" of Chieti-Pescara, Italy
}

\begin{abstract}
In the last years there has been a multiplication of the International and European political interventions addressed to the diffusion of environmental sustainability in the building sector. In this area the life cycle design of technical elements assumed particular relevance. The materials and construction techniques used, like their durability in the use phase and their disposal strategies, tend to influence the environmental behaviour of a building during its whole life cycle. It is worth recalling the energy consumption connected with the extraction, production and assembly of the materials (initial embodied energy) and with maintenance, replacement, and dismantling activities (lifecycle-embodied energy). At the present time the rules focusing on the environmental certification of technical elements allow one to meet these objectives only in part. The study that will be presented, based on eco-design and Life Cycle Assessment criteria, uses this knowledge to explain research work focused on a comparative evaluation of some technical elements, and analyzes different end of life scenarios, in order to further understanding and improve their environmental impact.
\end{abstract}

Keywords: eco-design, plaster coverings, life cycle assessment, reuse, recycling, construction waste reduction.

\section{Introductory remarks}

The present contribution synthesizes a research and experimentation job produced within the Italian Workgroup on the "Identification of minimum environmental criteria for the choice of building materials". The Workgroup works within the Management Commission of the NAP-GPP (National Action 
Plan for the Green Public Procurement) aiming at contextualizing, with regard to the national territory, the GPP criteria already developed by the European (CE COM 400/2008).

Within the Workgroup's activities two meaningful requirements emerged:

- the need to harmonize the above-mentioned criteria with the other instruments already adopted by the Public Administration for the planning and awarding of public contracts, such as the technological classification of building works (UNI 8290/1981 Italian system and SfB/1970 international system, in the version revised by the CIB-International Building Council) and price-lists to establish standardized costs, so as to be able to put economical information together with environmental information;

- the need to extend the analysis on the environmental behaviour of materials, products and building elements to the more meaningful phases of their life cycle (ISO/TS 21931-1/2006; CEN/TC 350, under development), so as to be able to integrate environmental criteria with indicators concerning the phases of use, maintenance and demolition, poorly documented by present-day environmental certification instruments, such as the EPD for building products (Environment Product Declaration, ISO 21930/2007) which refers prevalently to the extraction and production phases (from cradle to gate).

\subsection{Classification of building elements}

As far as the classification of technical elements is concerned, it is interesting to note how a division based on the single categories of usable materials would turn out to be rather fragmentary, in view of the present-day tendency towards the multi-materiality of building elements and the performance specialization of single functional layers. Therefore, it turns out to be easier to adopt the division defined by the Italian UNI 8290 rule and the international SfB system, both based on the identification of some "functional" categories, defined as "technological unit classes" (structures, closures, partitions, plants, etc.) and their subsets or "technological units", and of further "physical" categories of represented by "technical elements classes" and their subsets or "technical elements", which represent the manner to reply to the functions required of the technological units, obtained through the use of specific materials, products and building techniques. In this way, the technical element "wall" or "covering", for example, will be able to be constituted by a plurality of materials and products, joined in such a way as to obtain the expected final performances.

The building solutions adopted will define the correlation methods and joining of the single materials and products, and the workings necessary to guarantee respect for the overall technological performances (construction manner, functioning and maintenance mode, disassembly mode). At this level of in-depth examination, the technical forms associated with the selected materials and products will be able to supply a useful contribution to the knowledge of their specific characteristics and relative construction methods. Furthermore, once they have been developed and integrated, they will also be able to supply information regarding the product's environmental performance (Aninik et al [1]). The single materials (cement and concrete, clay bricks, wood and wood by- 
products, metals, etc.) and products (panels, fixtures, floors, façade systems, etc.) will thus be able to be identified depending on their belonging to a specific technical element, whose description will also include the workings necessary for their laying, and thus, lastly, the cost relating to the complete realization of the technical element itself.

\subsection{Environmental qualification of building elements}

In turn, environmental behaviour will be able to be easily identified both at a technical element level, as a summation of the specific environmental performances of the single materials, and at the level of single products, with particular reference to the extraction and production stages (including transports), building, maintenance and demolition. Exceptions are multi-coupled materials or materials mixed on the building site, and more generally multimaterial elements, separable with great difficulty at the end of their life. In that case, the environmental behaviour tied in with the demolition, too, will have to be associated with the whole technical element, or portions of it. However, generally speaking, it is possible to hypothesize the traceability of single materials and products inside the building and their specific environmental qualification, associated with corresponding certification of the producer. The most important is the aforementioned EPD, already developed for several product categories, also in the building sector (see: www.environdec.com).

While the task of arranging for the environmental qualification in the production/building phase is easily attributable to the executive firm, and its suppliers, the environmental qualification in the demolition phase is more difficult to manage, both because of the lack of specific certification instruments and for the lack of a consolidated environmental management system of the demolition works based on the separation of the residual products and the withdrawal of the recovered materials by the producers (Berge [2]). The implementation of such a system in contrast with the traditional transfer to landfill would produce meaningful environmental advantages, as is underlined in the ICLEI-Local Governments for Sustainability document "Construction Green Public Procurement Product Sheet” (see: www.iclei-europe.org).

\section{The case study: external plaster covering}

The case study presented tries to study in depth the aspects relating to the optimization of environmental behaviour in the life cycle of the technical elements of the building, through the analysis of a portion of the building element represented by an external plaster covering. In particular, it studies closely eco-design and environmental assessment aspects tied in with the utilization of different materials and constructive methods. The purpose of this is to be able to identify the most meaningful environmental impact and deduce from that, in an inductive way, a set of minimum environmental criteria.

The materials and building techniques taken as a reference are those most currently used in the execution of public and private works, both for new 
buildings and for the renewal of existing ones. Reference is made to cementbased plaster and hydrated lime-based plaster, these latter ones having been recently reassessed for their transpiration characteristics. Added to these, it was thought to be appropriate to add a further material used traditionally for the realization of plaster, represented by raw earth with lime, a low-intensity energy material which is being reintroduced for its capacity to combine further ecological qualities tied in with reduced environmental impact during the whole of its life cycle (Basti [3]) with the transpiration quality of hydrated lime. For all three materials, reference was made to the specific techniques of the producers and the descriptions of the executive methods contained in the technical specifications in terms of working phases, number and quantity of the single constituent layers. Furthermore, an industrialized type of productive process was hypothesized.

Table 1: An example of technological classification of the constructive solutions of external plaster covering analyzed.

\begin{tabular}{|c|c|c|c|c|c|}
\hline $\begin{array}{l}\text { Technological } \\
\text { unit class }\end{array}$ & $\begin{array}{c}\text { Technological } \\
\text { unit }\end{array}$ & $\begin{array}{c}\text { Technical element } \\
\text { class }\end{array}$ & $\begin{array}{c}\text { Technical } \\
\text { element }\end{array}$ & $\begin{array}{l}\text { Constructive } \\
\text { solution }\end{array}$ & $\begin{array}{c}\text { Materials and } \\
\text { products }\end{array}$ \\
\hline \multirow{6}{*}{ Shell } & \multirow{6}{*}{ Vertical shell } & \multirow{6}{*}{ Vertical perimeter wall } & \multirow{6}{*}{ External plaster } & \multirow{2}{*}{ By cement } & Dry mix \\
\hline & & & & & Water mixing \\
\hline & & & & \multirow{2}{*}{ By hidrated lime } & Dry mix \\
\hline & & & & & Water mixing \\
\hline & & & & \multirow{2}{*}{$\begin{array}{c}\text { By raw earth with } \\
\text { lime }\end{array}$} & Dry mix \\
\hline & & & & & Water mixing \\
\hline \multicolumn{2}{|c|}{ functional categories } & \multicolumn{4}{|c|}{ physical categories } \\
\hline
\end{tabular}
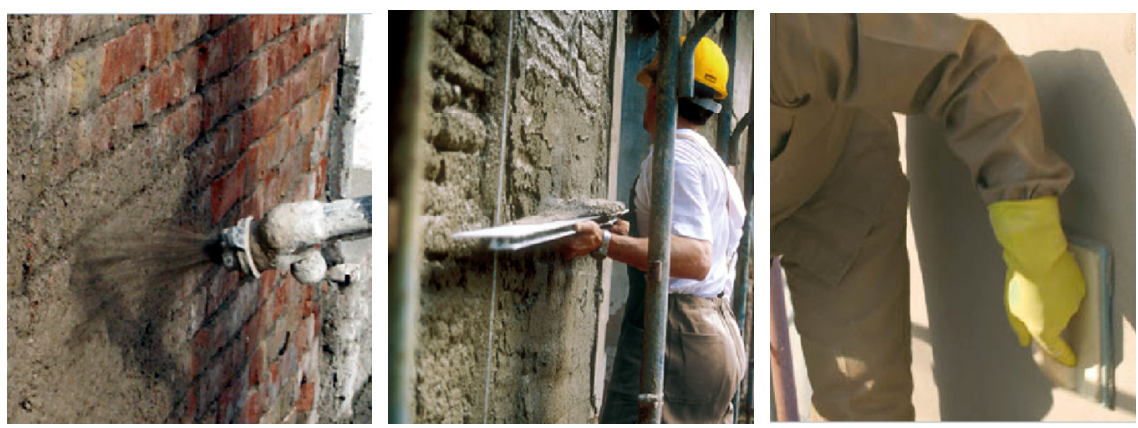

Figure 1: Realization phases of an external plaster (support, covering and finishing).

\subsection{Boundaries of the investigated system}

For the purpose of the study, it was considered important to adopt an assessment procedure of environmental behaviour divided into two levels of in-depth investigation. The first level aims at comparing the environmental impact produced by the same portion of the building element, represented by 1 square meter of external plaster covering (functional unit), carried out through the use of 
the different materials identified. At this level of in-depth investigation, attention is placed on the comparison of the impact generated in the whole life cycle.

For this purpose were considered the most meaningful life cycle phases, represented by the extraction and production of materials, the transport and mixing on the building site, and the end of life. The laying and maintenance stages have been omitted since literature does not consider them to have much impact. The first one because it is carried out prevalently by hand, the second one because the duration of the technical element has been assumed to coincide with the duration of the building (50 years), provided that maintenance interventions of the paintwork are carried out which, however, are not included in the system boundaries. As for the life end, in this first phase it was considered a traditional method for managing demolition waste, resulting in their transfer to landfill (AA. VV. [4]).

Instead, the second level of analysis aims at identifying the possible interventions for improving environmental behaviour with regard to the materials analyzed. For this purpose, it concentrates its attention on the life end phase, hypothesizing a different method for the management of demolition waste. The hypothesis of transfer to landfill is placed in contrast with the possibility of materials selection at a sorting plant, for their reuse as inert fillers.

With further regard to improving the environmental performance of the materials used, it must be remembered that further intervention could be identified also concerning the extraction and production phases. Interventions closely subordinate to the adoption of adequate strategies to increase efficiency in the use of resources and productive processes by producers (Bringezu [5]). Some actions lie outside the control capacity of the Public Authority, if there is not a request for environment qualification of the products at the contract stage. Hence it was decided to omit them from this study, which is primarily geared towards an assessment of a general nature and not tied to a specific product.

\subsection{Methodology and instruments}

For the purpose of simulation of environmental behaviour, it was considered important to make reference to the LCA methodology (Life Cycle Assessment), as an instrument internationally codified (ISO 14040/2006) and also acknowledged for the purpose of developing other instruments for environmental product qualification, such as ECOLABEL (EC Rule 1980/2000) and EPD (ISO $14025 / 2006$ and ISO 21930/2007). In particular, considering the aim of the study, it was considered important to adopt an approach of a selective type (screening LCA), more suitable for the development of comparative assessment and identification of improvement actions. For this purpose, an LCA software (SIMAPRO, PRE' Consultant) and inventory data from literature or from data banks associated with the software (ECOINVENT, PRE' Consultant) were used. Moreover it was considered important to develop the assessments relying on the ECO-INDICATOR 99 method (Geodkop and Spriensma [6]) as it prevalently refers to European territory, the same enquiry field as the European GPP programme. Finally, considered the public finality of the study, it was considered appropriate to make reference to the "egalitarian" profile, corresponding to a 
person with a strong collective conscience, and therefore more sensitive to environmental issues.

\subsection{Analysis and interpretation of the results: LCA of technical elements}

With reference to the first hypothesis (a traditional type of demolition waste management, consisting in their transfer to landfill), from a first analysis of environmental behaviour of the three types of materials used, it appears that the building solution (1 sq.m. functional unit) with the greatest impact is the one which uses "cement-based plaster", which produces overall damage in the life cycle of more than $26 \%$ in contrast with "hydrated lime-based plaster" $(0.23$ $\mathrm{pt} / 0,18 \mathrm{pt})$ and $53 \%$ in contrast with "raw earth with lime-based plaster" $(0.23$ $\mathrm{pt} / 0.15 \mathrm{pt})$.

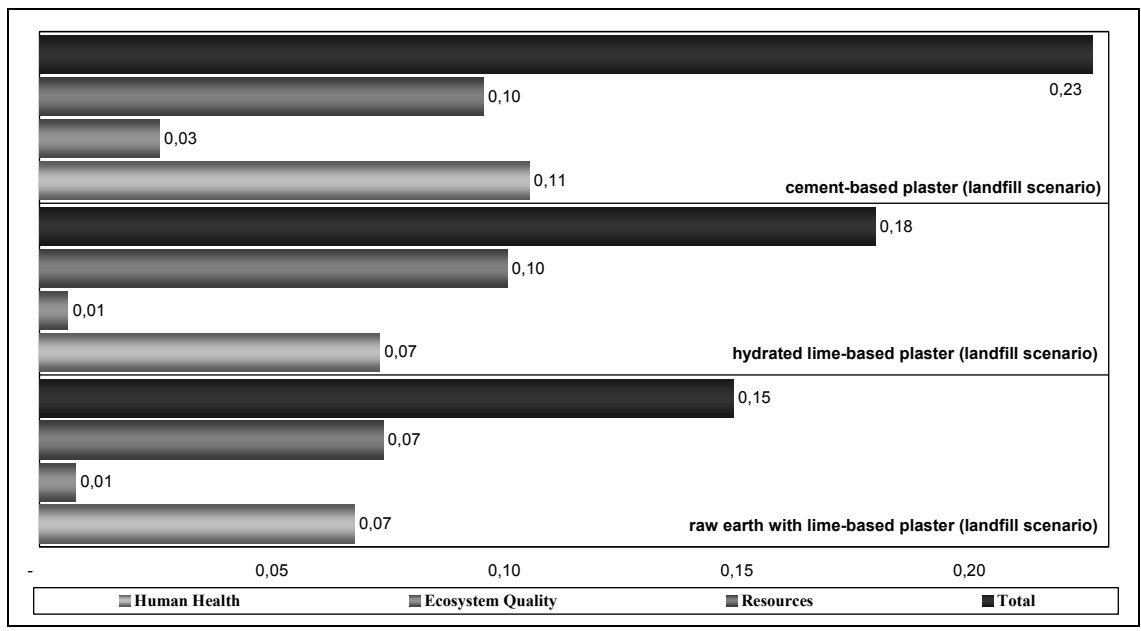

Figure 2: $\quad$ Environmental life cycle assessment of a part of external plaster (1 sq.m. functional unit) made with cement (above), hydrated lime (in the middle) and raw earth with lime (below) materials. End of life scenario with landfill (A. Basti, P. Milano elaboration).

It is interesting to note that environmental damage caused by the solution with cement plaster falls about halfway (46\%) into the HUMAN HEALTH category, because of the emissions of nitrogen monoxide, fine dust and carbon dioxide produced during the extraction and production stages (66\% of the category total). A further $42 \%$ is attributable to the RESOURCES category, this too generated in the extraction and production stages ( $77 \%$ of the category total) because of the use of petroleum (68\%), coal and natural gas $(26 \%)$. The hydrated lime-based solution, despite its having an overall inferior impact, reveals a greater use of resources $(+10 \%)$, caused by mostly energy-consuming production processes. Less meaningful is the impact concerning the ECOSYSTEM QUALITY 
category, prevalently generated by the activities of industrial transformation of the extractive sites. In this case, the impact generated by cement-based plaster prevails, which accounts for more than three times as regards raw earth with lime plaster and for more than four times as regards hydrated lime plaster (see figure 2).

The adoption of a different management strategy of demolition waste, consisting in the selection of materials at a sorting plant and their reuse as inert fillers, reveals interesting environmental advantages. In fact, it is possible to find a meaningful reduction of the impact, though the activities concerning the other stages of the life cycle remain unvaried. Cement plaster reduces its impact by $26 \%(0.17 \mathrm{pt} / 0.23 \mathrm{pt})$, hydrated lime-based plaster by $28 \%$ and raw earth with lime-based plaster by $40 \%$, also thanks to the lower amount of fine dust produced by this specific material in the demolition phase.

The most meaningful environmental advantages are realized in the RESOURCES category, which, thanks to the recovery and reuse of the inert waste, have a decreased of environmental impacts, variable from the $-30 \%$ (limebased plaster) to the $-51 \%$ (raw earth with lime-based plaster). Further, meaningful environmental advantages are realized in the HUMAN HEALTH category, thanks to the reduction of emissions into the air associated with the elimination of landfill activities and the reduction of future extractive processes (see figure 3). In this case, the values swing from the $-19 \%$ (cement based plaster) to the $-34 \%$ (raw earth with lime-based plaster).

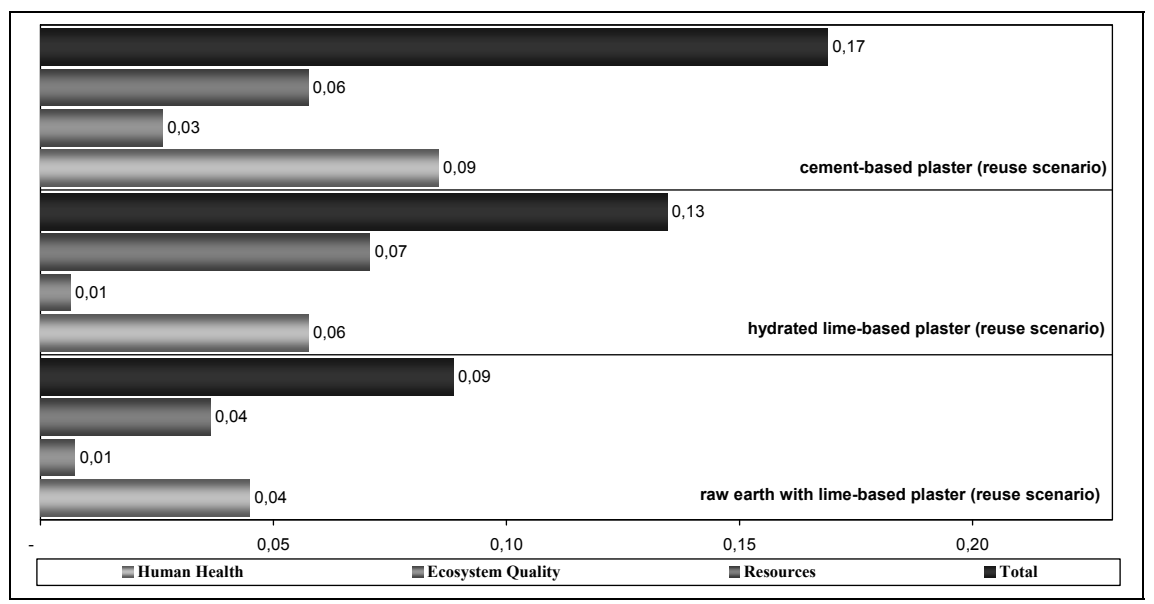

Figure 3: Environmental life cycle assessment of a part of external plaster (1 sq.m. functional unit) made with cement (above), hydrated lime (in the middle) and raw earth with lime (below) materials. End of life scenario with reuse (A. Basti, P. Milano elaboration). 


\subsection{Analysis and interpretation of the results: LCA of the demolition strategies of materials}

As we have already mentioned, the modelling of the disposal phase of materials (1 kg functional unit) was developed on the basis of two distinct hypotheses for the management of demolition waste, among which these alternatives:

- $\quad$ non-selective demolition with subsequent transfer of the residue to landfill.

- selective demolition with transport of the residue to sorting site and stockpiling, for subsequent reuse as inert filler.

In the first case, the inventory analysis was developed making reference to a disposal process from a databank (named: disposal, building, mineral plaster, to final disposal). The process includes emissions to air (particulates) produced during the dismantling and handling activities, the transport of residue to dismantling facilities, and their subsequent transfer to inert materials landfill. This latter activity allows for the incidence of the infrastructure used for the building, functioning and environmental requalification of the landfill facilities (calculated with regard to the amount of inert materials dealt with), and burdens relating to its functioning, represented by the land use and energy use. In this case, too, the data are obtained directly from databanks (named: Disposal, inert waste, $5 \%$ water, to inert material landfill).

The analysis reveals that the environmental damage caused by demolition activities and transfer of inert waste to landfill, is 39\% attributable to emission of

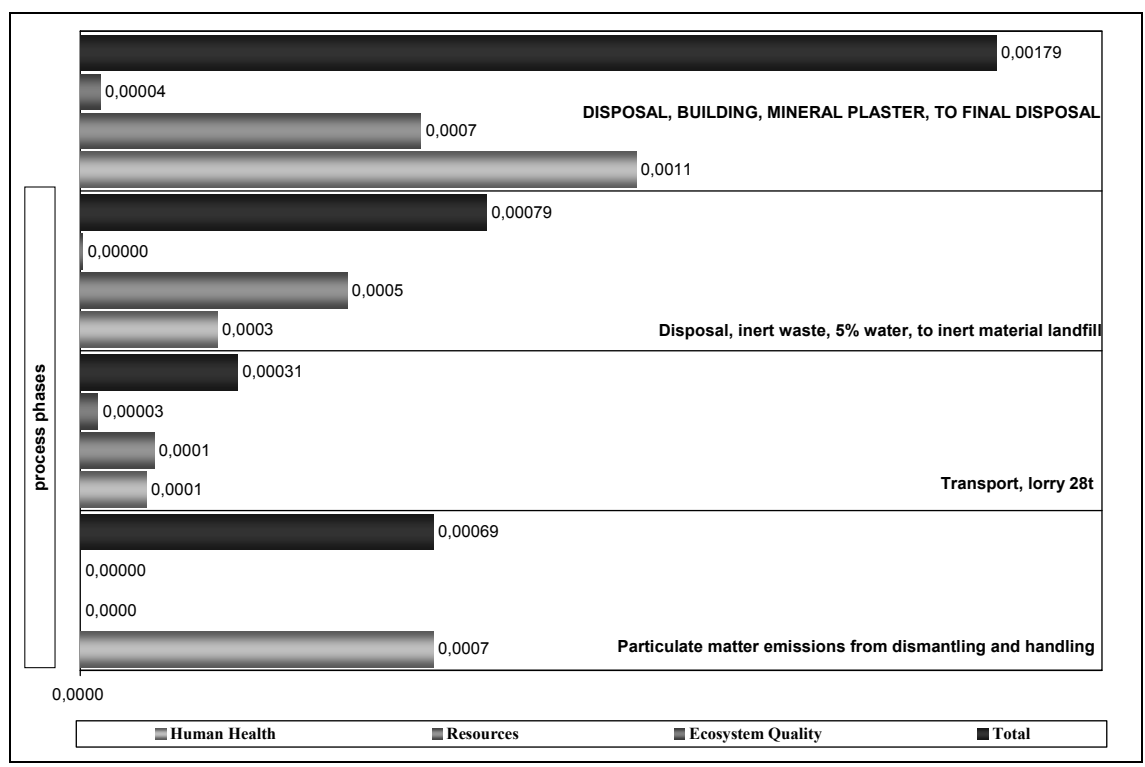

Figure 4: Environmental life cycle assessment of a disposal process of mineral plaster (1 kg functional unit). End of life scenario with landfill. 
particulates generated during the demolition works (HUMAN HEALTH category), and $44 \%$ to the impact produced by the inert material landfill itself (see figure 4). This activity prevalently weighs upon the preservation of resources and of human health. On the first because of the use of petroleum $(88 \%)$, natural gas and coal, on the second because of the emissions of nitrogen monoxide, fine dust and carbon dioxide (in the air) and of cadmium and arsenic ions (in the water).

In the second case, the inventory analysis was developed through the settingup of an "ad hoc" disposal process, so to bring out the greater environmental advantages subsequent to the life end strategy adopted. These advantages do not appear in the available databanks. This new disposal process take into account the environmental advantages obtained by two intervention categories:

- the recovery of inert materials, with subsequent elimination of the need to extraction of new virgin resources (product avoided: Gravel, unspecified, at mine);

- the elimination of the transfer of unseparated demolition waste to landfill (process avoided: Disposal, building, mineral plaster, to final disposal, already described in the first hypothesis).

The process (denominated: Disposal, building, plaster, to reuse) includes the energy absorption relating to demolition activities and the correlated particulate emissions, the energy use relating to the transport of demolition waste from the building site to the stockpiling site (considered coincident with the sorting plant),

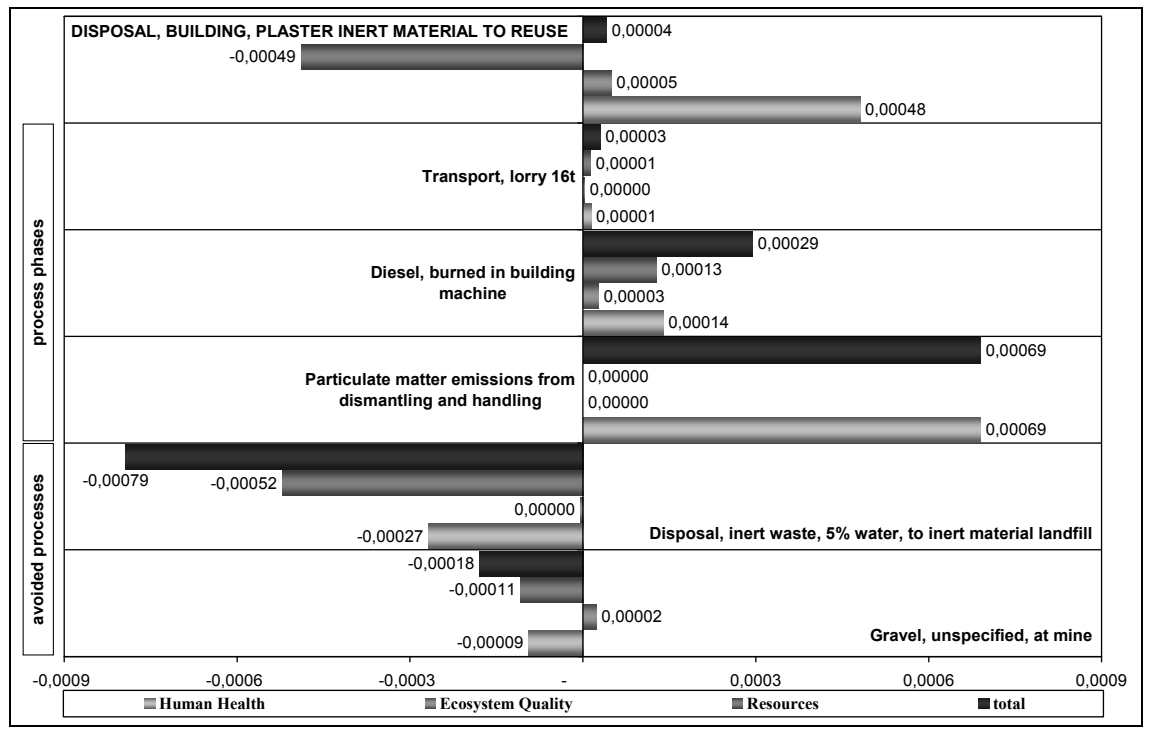

Figure 5: Environmental life cycle assessment of a disposal process of mineral plaster (1 kg functional unit). End of life scenario with reuse. Avoided processes are taken into account (A. Basti, P. Milano elaboration). 
the avoided processes relating to the recovery of inert materials and the avoided landfill. This latter process was taken from databanks, and considered corresponding to that used in the first hypothesis.

The analysis reveals an environmental advantage due to the processes avoided, which are able to compensate almost entirely the impact generated by the activities correlated to the demolition and transport of the residuals material, however present in both hypothesis (see figure 4 and 5).

The reuse of inert waste makes it possible to eliminate their contribution to landfill, with consequent advantages in terms of reducing the amount of waste produced, and hence in terms of extension of the landfill duration, and postponement of the need to open new landfills, with resulting consumption of other land. It also allows, as already mentioned, a reduction of the extraction of new mineral resources to use for subsequent productive processes and a consequent reduction of the environmental impact generated by them.

In the final analysis, it is possible to state that second hypothesis allows to obtain, being equal the impact generated in the preceding life cycle stages, a reduction of environmental damage during the life end management of about $97 \%$ (see figure 6) in contrast with what would happen by resorting to disposal systems presently in use, frequently based on an undifferentiated transfer of the material residues to landfill.

It is worth emphasizing that, for the analyses, it was considered make reference to the most favourable condition from an environmental point of view, that is, the transfer of the demolition residuals at an inert materials landfill. In fact, the impact generated by the transfer of the same demolition residuals to a Sanitary landfill (a controlled landfill for urban solid waste) would be different, as emerges from the following Figure 7.

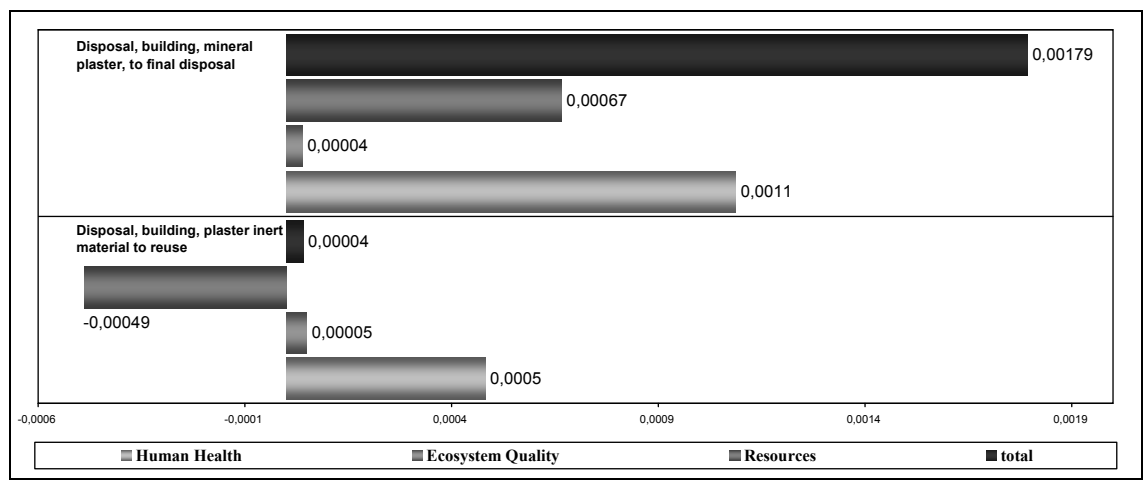

Figure 6: Environmental life cycle assessment of disposal processes of mineral plaster (1 kg functional unit) with landfill (above) or reuse (below) end of life scenario (A. Basti, P. Milano elaboration). 


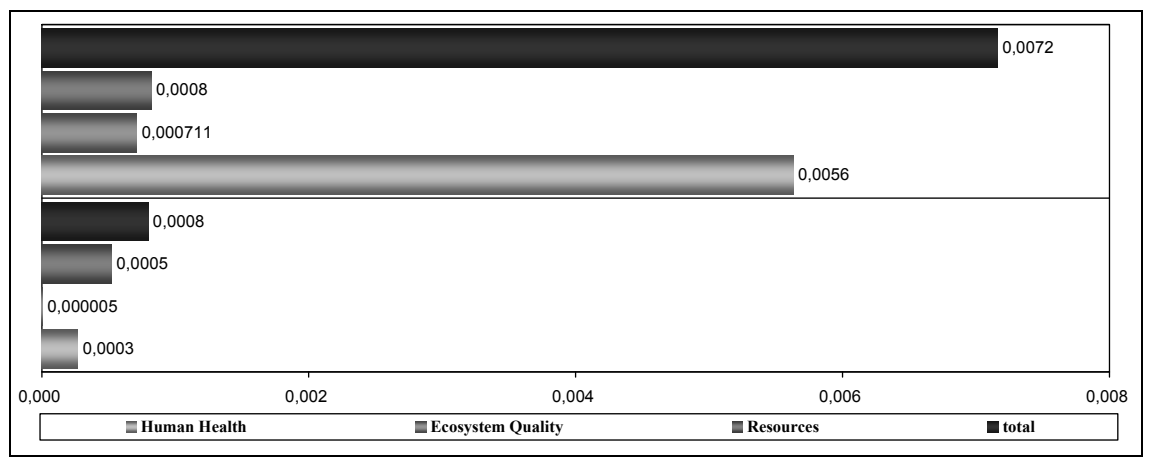

Figure 7: Environmental life cycle assessment of an end of life scenario for inert materials (1 kg functional unit), to a sanitary landfill (above) or to an inert material landfill (below).

\section{Conclusions}

These considerations tend to confirm what was said about the significant incidence of the management strategies of demolition waste, in relation to the overall impact generated by the individual technical elements of the building. With reference to the case study, it is possible to say that the introduction of some simple rules oriented to reuse of materials, could lead to a reduction of environmental impacts of about a quarter (with reference to cement plaster, see figure 3). A reduction that if combined with the choice of low impact building materials (with reference to raw earth-based plaster, see figure 2) could lead to a total reduction of approximately $60 \%$ (see figures 2 and 3 ). This despite the awareness of the various factors that affecting any LCA's study. The latter consideration suggests the opportunity to introduce between the environmental criteria for GPP, in addition to the possess of the above-mentioned EPD (useful to the choice of materials and products with less impact), more restrictive rules for the realization of building elements aimed at facilitating the separation of materials, their selection and reuse at the end of life. Criterion that needs to be combined with an effective action to support deployment of an enterprises network specialized on selective demolition, separation, shredding and waste treatment for their direct reuse or, at least, their recycling.

\section{Reference}

[1] Anink D., Boonstra C., Mak J., Handbook of Sustainable Building. An Environmental Preference Method for Selection on Materials for use in Construction and Refurbishment, James and James Science Publishers, London, (UK), 1996

[2] Berge J., The ecology of building materials, Elsevier Science Ltd, Oxford, (UK), 2000 
[3] Basti A., The environmental behavior of a "raw earth" building, in S. Briccoli Bati, M. Forlani, M. Germanà, S. Mecca, editors, Terra/TerreThe future of an ancient technology, ISBN 978-88-4672-146-4, ETS Edizioni, Pisa (IT), 2009

[4] AA. VV., Annex 31. Energy-Related Environmental Impact of Buildings, CMHC (Canada Mortgage and Housing Corporation) on behalf of IEA ECBCS (International Energy Agency-Energy Conservation in Buildings and Community), Canada, 2004

[5] Bringezu S. et al., Policy review on Decoupling: Development of indicators to assess decoupling of economic development and environmental pressure in the EU-25 and AC-3 countries, European Community, 2005

[6] Geodkop M., Spriensma R., The Eco-indicator 99, a damage-oriented method for life cycle assessment. Prè Consultant, (NL), 2000 